\title{
Continuous Intra-Abdominal Pressure Measurement: Re-Discovered
}

\author{
Zsolt Bodnar* \\ Letterkenny University Hospital, Ireland
}

Received: 剕: September 19, 2018; Published: 制 September 27, 2018

*Corresponding author: Zsolt Bodnar, Associate Professor, Letterkenny University Hospital, Letterkenny, Ireland

Abbreviations: Abdominal Compartment Syndrome (ACS); Intra-Abdominal Pressure (IAP); Continuous Intra Abdominal Pressure Monitoring (CIAPM)

\section{Introduction}

Last year was the 10th anniversary of the first publication on Polycompartment Syndrome. The term "Multiple Compartment Syndrome" was introduced by Scalea in 2007 suggesting the complex interplay between body compartments [1]. The "Polycompartment Syndrome" as a"terminus technicus" was published by Malbrain in the same year [2]. The human body is subdivided into smaller or larger units by well-defined compartments. The function of these compartments is to mechanically protect and separate the organs or organ systems situated inside them. Distinctively separated spaces of our bodies are the different fascial compartments, the skull, the spinal canal, the orbit, the pericardium, the thoracic and the abdominal cavities. The elasticity of the tissues of the separating walls (bone, muscle, connective tissue) have a strong determinative effect on the tolerance for volume or pressure changes exerted on the organs which can be found inside these compartments. Compartment syndrome in a wider sense defines those changes which occur in the given compartments due to the increased pressure (which apart from some lesser and/or greater fluctuations is constant under physiological circumstances) and to the decrease in local circulation developing in consequence of this. Detrimental effects of the increased pressure are widely known and precisely described in the medical literature [3].

Herniation syndromes occurring as a consequence of the increased intracranial pressure, the clinical appearance of pneumothorax and haemothorax caused by pathological accumulation of air or fluids inside the thoracic cavity, as well as the concept of pericardial tamponade are known by everybody and no one questions that all the above cases represent a compartment syndrome occurring as a consequence of the increased pressure having been elevated due to certain specific reasons. Upon mentioning, associations are immediately made to fascial compartments [2], however, the term compartment syndrome means the clinical picture of the entirety of pathophysiological alterations developing in consequence of the increased pressure occurring within a closed space; and this is irrespective whether the separating compartment itself is formed by the skull, the thorax, the abdominal cavity or a given fascial compartment. A common characteristic of these syndromes is the permanent and irreversible damage that may affect the organs which can be found inside the given compartment if quick intervention cannot be provided. If vital organs are affected these damages can be life-threatening or may even lead to death [3].

Abdominal compartment syndrome (ACS) was first described in relation to abdominal traumatic injuries. Kron was the first, who albeit did not use the term itself, yet described compartment syndrome in 1984. It was again Kron who routinely used abdominal pressure measurement through bladder catheterisation, which became widespread by 1989; however, the fundamentals of the method were described 100 years prior by Oderbrecht.

The fundamental principle of the method is the law which says that if pressure is exerted on the surface of a compartment predominantly containing some kind of fluid, then this pressure imposed upon the practically incompressible fluid will be transmitted unaltered to each and every point of the affected compartment. Consequently the intra-abdominal pressure (IAP) and the intravesical pressure values are strictly identical. If the bladder is filled with $50 \mathrm{~mL}$ of physiological saline and the previously inserted catheter is closed, then the pressure predominating the bladder will be transmitted to the catheter and became easily measurable through a sterile needle inserted into the catheter (intermittent pressure measurement). To surmount points of weakness (laboursome, intermittent) Balogh and his working group developed and validated the method of continuous intraabdominal pressure monitoring (CIAPM) [4]. 


\section{Intermittent Pressure Measurement}

The patients wore a simple bladder catheter (Foley balloon catheter, $16 \mathrm{Fr}-20 \mathrm{Fr}$, latex or silicone). During the measurement the urine collection bag was removed and the bladder was filled with 50 $\mathrm{mL}$ of physiological saline through the lumen of the catheter. In the next step the lumen of the catheter was connected to a set designed and used for the measurement of the central venous pressure (B. BRAUN Medifix® pressure measurement scale) with or without the insertion of a T-tap. The zero point of the scaled measurement tube was designated in the medioaxillary line corresponding to the anterior superior iliac crest. After waiting 1-2 minutes, at the end of exhalation the value of IAP could be read off the scale in unites of $\mathrm{cmH}_{2} \mathrm{O}$. The values read off should be converted to $\mathrm{mmHg}$ $\left(1 \mathrm{mmHg}=1.36 \mathrm{cmH}_{2} \mathrm{O}\right)$. When the measurement was completed the system and the bladder catheter were disconnected and the latter was connected to a urine collection bag.

\section{Continuous Intra-Abdominal Pressure Measurement}

For the measurements we used $18 \mathrm{Fr}$ standard three-way bladder catheters (LubriSilTM All-Silicone Foley catheter, C.R. Bard, Inc., Covington, GA, U.S.A.). The catheter and the urine collecting bag remained connected for all the time. In order to perform the pressure measurement the so called flushing port of the catheter was connected with the insertion of a transducer to a 24-hour bedside monitor. The connection of the flushing port and the transducer was effectuated with a triple tap. The collapse of the bladder was prevented with physiological saline continuously perfused with the speed of $4 \mathrm{~mL} / \mathrm{h}$. The zero point for the fixation of the transducer was established in the plane determined by the axillary median line and the anterior superior iliac crest. After the system was set to zero the measured data were continuously recorded, which data could be easily read off from the bedside monitor. The actual IAP value appeared directly in $\mathrm{mmHg}$ and required no further conversion. Pressure values were read off in every hour. The IAP mean value determined on a daily basis was calculated as the average of pressure values recorded in 24 hours [5].

Although the intermittent technique is simple, yet timeconsuming; requiring 5 to 7 minutes depending on the practice of the staff. Performance of the measurement is compulsory for at least four times per day per patient, i.e. from the staff providing the care it requires plus work of at least a half an hour even in the case of a single patient. Filling of the catheter and its connections and disconnections are infection sources. The measurement results provide information only on the individual pressure values of the pre-determined measurement dates. In order to eliminated these weak points mentioned and for the safe and quick measurements the classical technique was replaced with a completely new method. Following its first construction the system of CIAPM can be operated without interruption until the next replacement of the bladder catheter ( 7 to 10 days), thereby eliminating the risk of infection originating from the catheter replacements in the intermittent measurements, as well as the need for extra work and tools. In order to further test of the CIAPM, intermittent and continuous measurements were carried out in patients admitted due to acute pancreatitis. Intra-abdominal pressure was determined with both methods in case of all patients (Figures 1\&2).

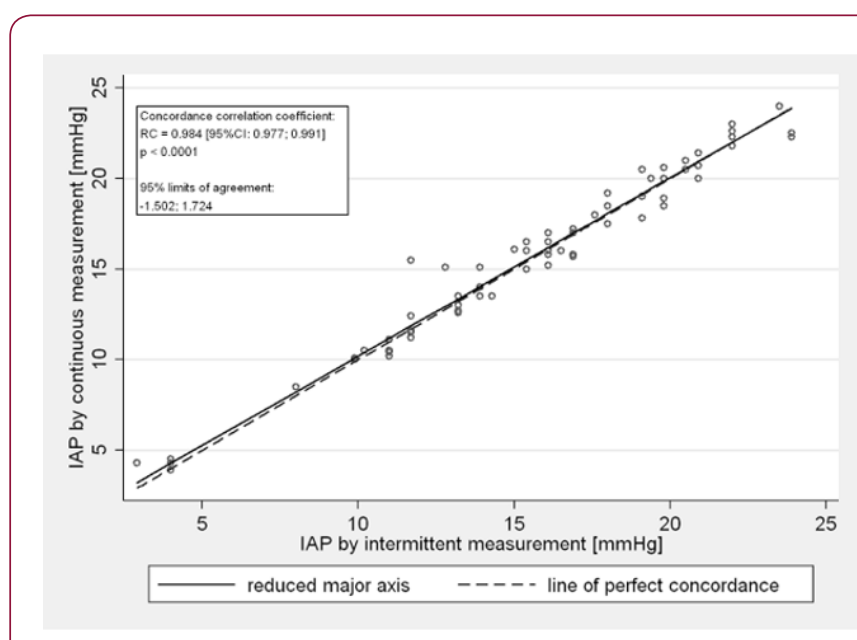

Figure 1: The concordance correlation coefficient was higher than 0.97 in all cases.

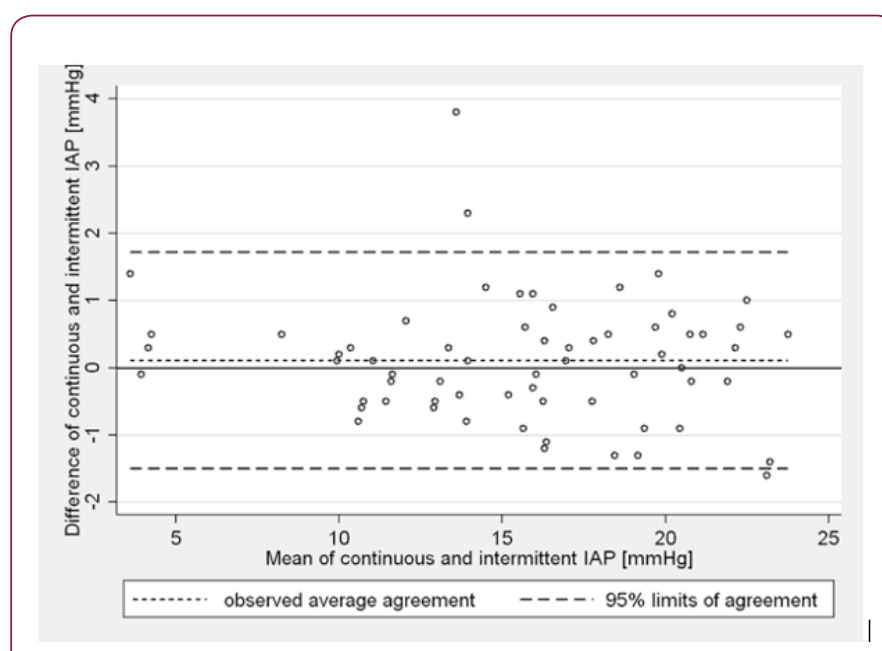

Figure 2: The Bland-Altman statistical analysis resulted that the $95 \%$ limits of agreement was between the nonsignificant $\pm 2 \mathrm{mmHg}$ range.

Significant difference could not be observed between the results of the intermittent measurements and of the new technique. According to the statistical analysis the concordance correlation coefficient was higher than 0.97 in all cases, which shows a strongly significant agreement between the two different techniques. The 95\% limits of agreement of the Bland-Altman method were between the non-significant $\pm 2 \mathrm{mmHg}$ range. According to our results we can summarize that the continuous intra-abdominal pressure monitoring technique is a modern, safe and accurate method for the IAP monitoring, which provides results immediately, in $\mathrm{mmHg}$ without need of conversion. The measurement of IAP is essential in development of polycompartment syndrome. Clinicians need to be aware of the real exictence of different compartment syndromes and the complex and constant interplay of raised pressure between compartments[6]. 


\section{References}

1. Scalea TM, Bochicchio GV, Habashi N (2007) Increased intra-abdominal, intrathoracic and intracranial pressure after severe brain injury: multiple compartment syndrome. J Trauma 62(3): 647-656.

2. Malbrain ML, Wilmer A (2007) The polycompartment syndrome: towards an understanding of the interactions between differentcompartments Int Care Med 33(11): 1869-1872.

3. Balogh Zs, Butcher N (2010) Compartment syndrome from head to toe. Crit Care Med 38(9):445-451.

ISSN: 2574-1241

DOI: 10.26717/BJSTR.2018.09.001795

Zsolt Bodnar. Biomed J Sci \& Tech Res

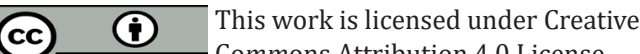

Submission Link: https://biomedres.us/submit-manuscript.php
4. Iberti TJ, Kelly KM, Gentili DR, Hirsch S, Benjamin E (1987) A simple technique to accurately determine intra-abdominal pressure. Crit Care Med 15: 1140-1142.

5. Balogh Zs, Jones F, D Amours S ( 2004) Continuous intra-abdominal pressure measurement technique. Am J Surg 188(6): 679-684.

6. Bodnar Zs, Keresztes T, Kovacs I ( 2010) Increased serum adenosine and interleukin-10 levels as new laboratory markers of increased intraabdominal pressure. Langenbeck Arch Surg 395: 969-972.

$\begin{array}{ll}\text { BIOMEDICAL } & \text { Assets of Publishing with us } \\ \text { RESEARCHES } & \text { - Global archiving of articles } \\ \text { - Immediate, unrestricted online access } \\ \text { https://biomedres.us/ }\end{array}$

